\title{
Thyroid lymphoepithelial nodule
}

\author{
A. Handra-Luca1, 2, E. Dragoescu ${ }^{3}$ \\ ${ }^{1}$ Service d'Anatomie Pathologique, APHP GHU Avicenne, Bobigny, France \\ ¿Universite Paris Nord Sorbonne Cite, Bobigny, France \\ ${ }^{3}$ Department of Pathology, Virginia Commonwealth University Health System, Richmond, Virginia, United States
}

[Received 31 March 2014; Accepted 6 May 2014]

Thyroid benign lymphoepithelial lesions are rare in adults, reported as associated with thyroiditis or adjacent to tumours. Here we report a unique case of a thyroid solid nodule with benign lymphoepithelial morphology.

A 56-year-old woman presented with a thyroid nodule increasing in size. Thyroid function was normal. On the surgical resection specimen, in addition to a 2-cm follicular adenoma, there was, at distance, a $0.5-\mathrm{cm}$ solid nodule with lymphoepithelial morphology, without Hassal's corpuscles or calcifications. On immunohistochemistry, the epithelial component was cytokeratin 5/6 positive and very focally cytokeratin 7 positive, the immunophenotype of the lymphoid tissue confirming the benign nature. The diagnosis of thyroid benign lymphoepithelial nodule was proposed.

In conclusion, recognition of thyroid solid benign lymphoepithelial nodules is important since they can be misdiagnosed with other thyroid micronodule types including carcinoma, primary or metastatic. (Folia Morphol 2014; 73, 4: 507-509)

Key words: Iymphoepithelial nodule, micronodule, thyroid

Thyroid benign lymphoepithelial lesions are rare in adults, reported as having cystic morphology and associated with chronic lymphocytic, Graves or Hashimoto thyroiditis. In addition, they may occur at the periphery of thyroid papillary carcinoma or lymphoma $[2,3,6,8,9,11,12]$. We report here a unique type of thyroid lymphoepithelial lesion with solid, nodular growth morphology.

A 56-year-old female presented with a right thyroid nodule that has recently increased in size. There were no signs of abnormal thyroid function (TSH was within normal range, $1.78 \mathrm{mU} / \mathrm{L}$ ). The patient had a history of arterial hypertension (treated by losartan and hydrochlorothiazide), potassium chloride intake and, laparoscopic oophorectomy (unknown date and diagnosis). Right thyroid lobectomy with isthmusectomy was performed. The surgical specimen contained two grossly visible nodules: a $2 \mathrm{~cm}$ nodule in the right lobe and a $0.5 \mathrm{~cm}$ nodule in the isthmus. On microscopy, the largest nodule was a follicular adenoma. The second nodule had a rounded contour with well delimited borders surrounded in part by a thin layer of connective tissue (Fig. 1). The nodule consisted of abundant benign lymphoid tissue with several follicles with germinal centres. There was a circular rim of uniform, nondescript epithelial cells, of varied thickness, with no clear glandular or squamous differentiation, no keratinisation or keratinous debris. These cells were focally infiltrated by lymphocytes. No thyroid follicular cells were noted within the nodule. There was no cystic degeneration or cavity formation, including collapsed cysts. In addition, calcifications or Hassall's corpuscles were not observed. The epithelial cells expressed cytokeratin AE1/AE3, cytokeratin 5/6,

Address for correspondence: A. Handra-Luca, MD, PhD, Service d'Anatomie Pathologique, APHP GHU Avicenne, Universite Paris Nord Sorbonne Cite 125, rue de Stalingrad, 93000 Bobigny, France, tel: +33 148955555 ext. 2047/5601, fax: +33 148955602, 
and very focally cytokeratin 7 , and were negative for cytokeratin 20 (Fig. 1). Thyroid transcription factor (TTF1) showed faint, focal nuclear expression in some of the cells; however, it was less intensely expressed than in the surrounding normal thyroid tissue. Immunohistochemistry for CD20, CD3, CD5, CD10, CD23, bcl2, and Ki67 confirmed the benign nature of the lymphoid tissue. Overall, this $0.5 \mathrm{~cm}$ isthmic lesion had the morphology of a solid benign lymphoepithelial nodule.

Here we report an incidentally found thyroid nodule with a solid lymphoepithelial morphology, reminiscent of the minute thyroid lymphoepithelial complexes reported by Carney [1]. Histologically, this nodule was composed of benign lymphoid tissue with well-formed follicles with germinal centres and a circular rim of uniform, nondescript epithelial cells. This dual combination of epithelial-lymphoid elements is similar to the parotid benign lymphoepithelial lesion seen in association with Sjogren syndrome [4]. It is also reminiscent of the wall of a lymphoepithelial cyst; however, in this nodule there was no cystic formation, even in a collapsed or compressed variant $[2,4]$. It is reasonable to consider that this small-sized nodule may have developed cystic degeneration over time along with growth in size. An important observation is that the immunoprofile of the epithelial cells forming the lymphoepithelial nodule indicated rather a non-thyroid follicle origin. Although a faint TTF1 expression was noted in some of the cells, this was less intense than the surrounding thyroid follicular cells. Of note, TTF1 expression is noted in branchial cleft cysts as well [7]. Therefore, one may question the origin of this lymphoepithelial nodule. An embryologic remnant of the pharyngeal arch could be a possibility. The resemblance to normal adult tonsillar tissue is striking, except for the absence of definite squamous differentiation with keratin production. A pharyngeal/branchial arch origin was suggested in the literature for several entities or spectrum of lesions, such as: solid cell nests, intrathyroidal thymic and parathyroid mature tissue or immature remnants, and thyroid lymphoepithelial cysts $[6,11,12]$. However, pharyngeal arch remnants are usually located in the anterolateral region of the neck [12], not midline like our case. The hypothesis that this nodule may represent an intrathyroid thymic tissue is unsubstantiated. No Hassall's corpuscles, calcified or not, were present, although the epithelial component expressed cytokeratin 5/6 [5]. In addition, to our knowledge,

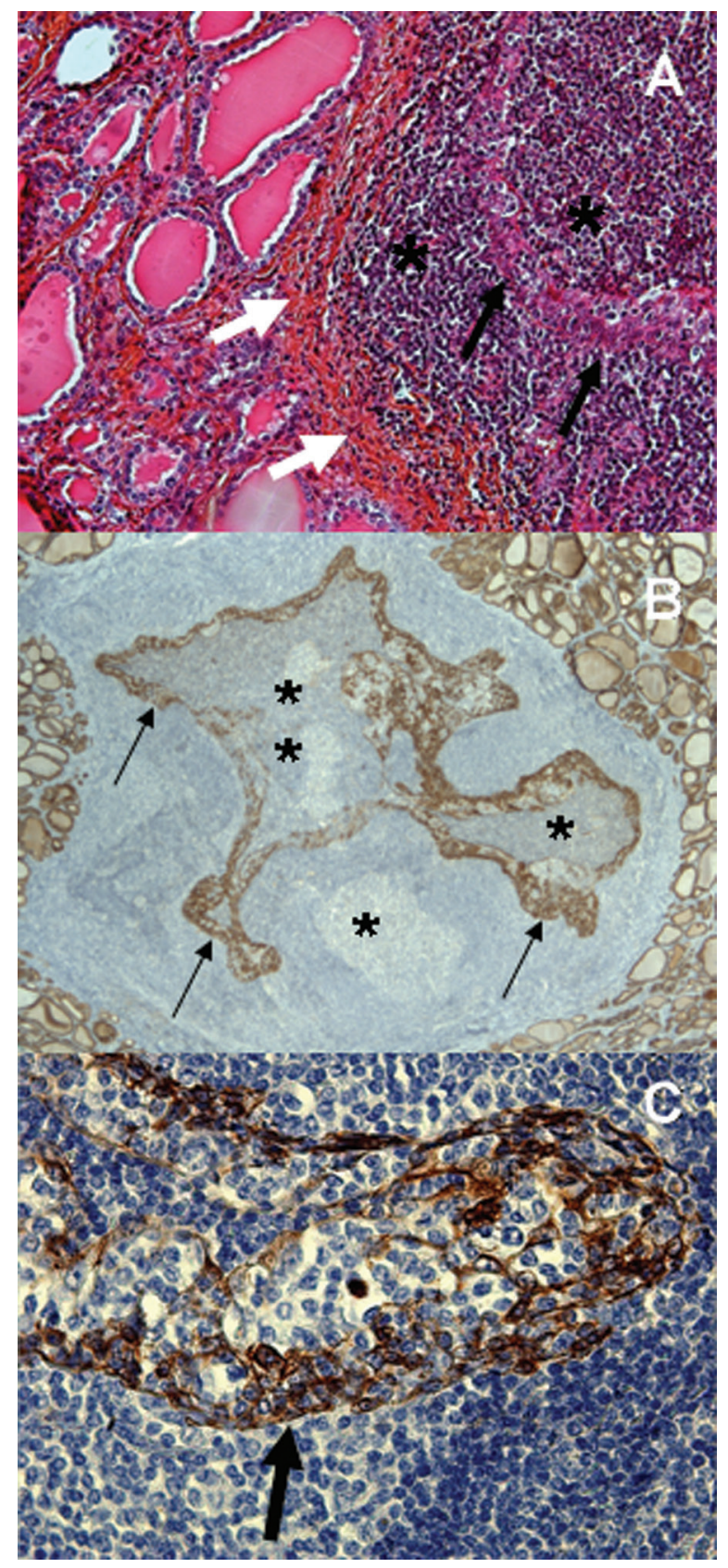

Figure 1. The intrathyroid nodule consisted of abundant, benign, lymphoid tissue (A. Haematoxylin and eosin stain; B. Cytokeratin AE1/AE3 immunohistochemistry: stars) and a circular rim of epithelial cells (A, black arrows) expressing cytokeratin AE1/AE3 (B, arrows). Focally a thin collagen layer surrounded the nodule (A, white arrows). The epithelial cells expressed cytokeratin $5 / 6$ (C, arrow). Original magnification $\times 10, \times 5, \times 20$ for $A, B$, and, $C$, respectively.

the presence of intrathyroid normal thymus has been reported only in the paediatric patients while in adults only with regard to tumours known to develop from thymic tissues $[8,12]$. There are reports however, of thyroid-associated-lymphoid tissue showing thymic 
cortex and medulla and a thymus-specific lymphocyte pattern developing in Wistar rats after an enriched iodine diet [10].

In the present case, this benign lymphoepithelial nodule was an incidental finding of no clinical relevance at the time of surgery. However, it deserves to be reported since, to the best of our knowledge, the isolated, solid morphology of a thyroid lymphoepithelial lesion has not been described in the literature to date. Recognising this thyroid lesion is important since it can be confused with other types of thyroid micronodules [11, 12].

\section{ACKNOWLEDGEMENTS}

The authors thank Dr A. Weissferdt, Dr M. Pusztazeri, Dr L. Jan, Prof. A. Ryska and Prof. J. Matias-Guiu. We also thank Dr I. Laouar, I. Alexandre, F. Spindler, and O. Ferreira, and acknowledge Prof. M.C. Ouayoun involved in the management of the patient.

\section{REFERENCES}

1. Carney JA (1989) Thyroid cysts. Am J Surg Pathol, 13: 1072-1074.

2. Choi CJ, Choi SW, Cho JG, Woo JS (2010) Bilateral lymphoepithelial cysts of the thyroid gland. Thyroid, 20: 111-113.
3. Delabie J, De Wolf-Peeters C, Cappelle L, Van Damme B, Desmet V (1990) Branchial cleftlike cysts of the thyroid. Am J Surg Pathol, 14: 1165-1167.

4. Ellis GL, Auclair PL (1996) Tumors of the Salivary Glands. AFIP fascicle 17, 3rd series. Armed Forces Institute of Pathology, Washington DC.

5. Handra-Luca A (2014) Subangulomaxillary cyst containing vestigeal remnants with thymic and parathyroid differentiation in an adult HIV1-positive patient. Int J Surg Pathol, 22: 93-95.

6. Khan A (2009) Surgical pathology of endocrine and neuroendocrine tumors. Humana Press, New York.

7. Kreft A, Hansen T, Kirkpatrick CJ (2005) Thyroid transcription factor 1 expression in cystic lesions of the neck: an immunohistochemical investigation of thyroglossal duct cysts, branchial cleft cysts and metastatic papillary thyroid cancer. Virchows Arch, 447: 9-11.

8. Louis DN, Vickery AL Jr, Rosai J, Wang CA (1989) Multiple branchial cleft-like cysts in Hashimoto's thyroiditis. Am J Surg Pathol, 13: 45-49.

9. Matias-Guiu X, Esquius J (1991) Lymphoepithelial lesion in the thyroid. A non-specific histological finding. Pathol Res Pract, 187: 296-300.

10. Mooij P1, de Wit HJ, Drexhage HA (1994) A high iodine intake in Wistar rats results in the development of a thyroid-associated ectopic thymic tissue and is accompanied by a low thyroid autoimmune reactivity. Immunology, 81: 309-316.

11. Rosai J, Carcangiu ML, DeLellis RA (1992) Tumors of the thyroid gland. AFIP fascicle $5.3^{\text {rd }}$ series. Armed Forces Institute of Pathology, Washington DC.

12. Rosai J (2011) Rosai and Ackerman's surgical pathology. $10^{\text {th }}$ Ed. Elsevier, Philadelphia. 